\title{
Pyrophosphate Supplementation Prevents Chronic and Acute Calcification in ABCC6-Deficient Mice
}

Viola Pomozi, ${ }^{*}$ Christopher Brampton, ${ }^{*}$ Koen van de Wetering, ${ }^{\dagger}$ Janna Zoll, ${ }^{*}$ Bianca Calio, ${ }^{*}$ Kevin Pham,$*$ Jesse B. Owens, ${ }^{\ddagger}$ Joel Marh, ${ }^{\ddagger}$ Stefan Moisyadi, ${ }^{\ddagger}$ András Váradi, ${ }^{\S}$ Ludovic Martin, ${ }^{\mathbb{T} \|}$ Carolin Bauer, ${ }^{* * \dagger \dagger}$ Jeanette Erdmann, ${ }^{* * \dagger \dagger}$ Zouhair Aherrahrou, ${ }^{* * \dagger \dagger}$ and Olivier Le Saux*

From the Department of Cell and Molecular Biology* and Institute for Biogenesis Research, ${ }^{\ddagger}$ John A. Burns School of Medicine, University of Hawaii, Honolulu, Hawaii; the Department of Dermatology and Cutaneous Biology, ${ }^{\dagger}$ Sidney Kimmel Medical College, PXE International Center of Excellence in Research and Clinical Care, Thomas Jefferson University, Philadelphia, Pennsylvania; the Institute of Enzymology, ${ }^{\S}$ Research Centre for Natural Sciences, Hungarian Academy of Sciences, Budapest, Hungary; the Université Bretagne-Loire, "Integrated Neurovascular and Mitochondrial Biology, National Center for Scientific Research 6214/INSERM 1083, Angers, France; University Hospital Angers," Center for PXE Consultation, Angers, France; the Institut für Integrative und Experimentelle Genomik Universität zu Lübeck, ** German Centre for Cardiovascular Research, Partner Site Hamburg/Kiel/Lübeck, Germany; and the University Heart Centre Lübeck, ${ }^{\dagger \dagger}$ Universität zu Lübeck, Lübeck, Germany

Accepted for publication

February 16, 2017.

Address correspondence to Olivier Le Saux, Ph.D., Department of Cell and Molecular Biology, John A. Burns School of Medicine, University of Hawaii, 651 Ilalo St, BSB222E, Honolulu, HI 96813. E-mail: lesaux@hawaii. edu.

\begin{abstract}
Soft tissue calcification occurs in several common acquired pathologies, such as diabetes and hypercholesterolemia, or can result from genetic disorders. $A B C C 6$, a transmembrane transporter primarily expressed in liver and kidneys, initiates a molecular pathway inhibiting ectopic calcification. ABCC6 facilitates the cellular efflux of ATP, which is rapidly converted into pyrophosphate (PPi), a major calcification inhibitor. Heritable mutations in $A B C C 6$ underlie the incurable calcification disorder pseudoxanthoma elasticum and some cases of generalized arterial calcification of infancy. Herein, we determined that the administration of PPi and the bisphosphonate etidronate to $A b c c 6^{-/-}$mice fully inhibited the acute dystrophic cardiac calcification phenotype, whereas alendronate had no significant effect. We also found that daily injection of PPi to $A b c c 6^{-/-}$mice over several months prevented the development of pseudoxanthoma elasticum-like spontaneous calcification, but failed to reverse already established lesions. Furthermore, we found that the expression of low amounts of the human ABCC6 in liver of transgenic $A b c c 6^{-1-}$ mice, resulting in only a $27 \%$ increase in plasma PPi levels, led to a major reduction in acute and chronic calcification phenotypes. This proof-of-concept study shows that the development of both acute and chronic calcification associated with $A B C C 6$ deficiency can be prevented by compensating PPi deficits, even partially. Our work indicates that PPi substitution represents a promising strategy to treat ABCC6-dependent calcification disorders. (Am J Pathol 2017, 187: 1258-1272; http://dx.doi.org/10.1016/j.ajpath.2017.02.009)
\end{abstract}

Pathological (ectopic) mineralization of soft tissues occurs during aging and in several common acquired conditions, such as diabetes, hypercholesterolemia, renal failure, and certain genetic disorders. Metabolic, mechanical, and inflammatory injuries contribute to ectopic calcification through distinct molecular mechanisms of initiation and inhibition. ${ }^{1}$ Several mechanisms have evolved to prevent ectopic calcification. One of these involves ABCC6, a transmembrane protein primarily found in the plasma membrane of hepatocytes and renal proximal tubule epithelial cells. ${ }^{2}$ ABCC6 is an ATP-dependent organic anion transporter. ${ }^{3}$ Since the first evidence that ABCC6
Supported by NIH grants HL108249 (O.L.S.), G12 MD007601, P30 GM103341 RR003061, P20GM103457, the Ingeborg v.F. McKee Fund of the Hawaii Community Foundation grant 15ADVC-74403 (O.L.S.), and The Hungarian grants OTKA 114136, 104227, and OTKA K111625 (all to A.V.). Additional funding was provided by the German Federal Ministry of Education and Research (BMBF - e:AtheroSysMed and sysINFLAME), the FP7 European Union project CVgenes@target (261123), the Fondation Leducq (CADgenomics: Understanding Coronary Artery Disease Genes, 12CVD02), the Medizinische Genetik of the Universität zu Lübeck, and the Deutsche Forschungsgemeinschaft cluster of excellence Inflammation at Interfaces (Z.A.). PXE International Inc. provided support (K.v.d.W.).

V.P. and C.B. contributed equally.

Z.A. and O.L.S. contributed equally as senior authors.

Disclosures: None declared. 
function relates to calcification inhibition, ${ }^{4,5}$ the identification of an endogenous substrate(s) has been infructuous despite many attempts. ${ }^{6}$ However, the main consequence of ABCC6 molecular function has now been established as a mediator of nucleotide efflux, of which ATP appears most relevant to ectopic calcification. ${ }^{7,8}$ Indeed, cells expressing human ABCC6 excrete large amounts of nucleotide triphosphates. The extracellular domains of ectonucleotide pyrophosphatase phosphodiesterase 1 (ENPP1) and ecto-5'nucleotidase (alias CD73) quickly convert the excreted ATP to pyrophosphate (PPi) and adenosine. ABCC6 dysfunction leads to lower cellular efflux of ATP and the subsequent production of extracellular PPi. ABCC6 is responsible for approximately $60 \%$ of the PPi in plasma. ${ }^{7} \mathrm{PPi}$ is a potent inhibitor of hydroxyapatite crystallization ${ }^{9}$ and is the main inhibitor of vascular and other tissue calcification in the body. ${ }^{10}$ Therefore, ABCC6 deficiency underlies several related calcification disorders. Pseudoxanthoma elasticum (PXE; Online Mendelian Inheritance in Man 264800; prevalence, approximately $1: 25,000)$ is characterized by late-onset and progressive (chronic) calcifications in the skin, vascular, and ocular tissues. ${ }^{4,5,11}$ Generalized arterial calcification of infancy (GACI; Online Mendelian Inheritance in Man 208000; prevalence, unknown) is typically associated with ENPPI mutations and results in early patient mortality. However, some GACI patients only carry ABCC6 mutations. ${ }^{12}$ The calcification phenotype associated with $\beta$-thalassemia (Online Mendelian Inheritance in Man 187550; prevalence, 1:10,000 around the Mediterranean basin) probably results from a progressive reduction of ABCC6 expression. ${ }^{13,14}$ ABCC6 dysfunction in mice also causes an acute inducible phenotype referred to as dystrophic cardiac calcification (DCC). ${ }^{15,16}$ These diseases are incurable.

Bisphosphonates, nonhydrolyzable analogs of PPi, were tested as a treatment for GACI and against the chronic calcification phenotype of $A b c c 6^{-1-}$ mice. Early treatments improved GACI outcome, ${ }^{17}$ but provided mixed results in mice. ${ }^{18}$ Inorganic pyrophosphate was suggested in the early 1960s as a possible treatment for ectopic calcification, and it is now considered with renewed interest despite its short half-life in plasma. ${ }^{19-24}$ Therefore, to address the hypothesis that normalizing the levels of PPi could counteract the pathology of PXE and DCC, we investigated whether PPi and bisphosphonate supplementation could prevent and/or reverse acute and chronic calcification in Abcc6-deficient mouse models.

\section{Materials and Methods}

Animals

C57BL/6J mice, designated herein as wild type, were derived from mice purchased from Jackson Laboratories (Bar Harbor, ME). Purchased mice were allowed at least 2 weeks of acclimation before being included in experiments.
Abcct $^{\text {tmlAabb }}$ mice were generated on 129/Ola background ${ }^{25}$ and backcrossed into a C57BL/6J $>10$ times. These mice are herein designated $A b c c 6^{-/-}$. Both male and female, agematched $A b c c 6^{-/-}$and wild-type mice were used, as sex had no significant impact on results. All animals were housed in approved animal facilities at the University of Hawaii School of Medicine. Mice were kept under routine laboratory conditions with 12-hour light-dark cycle with ad libitum access to water and chow. The University of Hawaii Institutional Animal Care and Use Committees approved these studies. Experiments were conducted according to the NIH Guide for the Care and Use of Laboratory Animals. ${ }^{26}$

\section{Liver-Specific Expression of ABCC6 cDNA in Mice}

Inducing the transient expression of a specific cDNA by hydrodynamic tail vein injection (HTVI) has been described previously. ${ }^{27-29}$ Briefly, a cDNA encoding human ABCC6 was subcloned into the pLIVE vector carrying the mouse albumin promoter and a fetoprotein enhancer that ensured a liver-specific expression (Mirus Bio, Madison, WI). The plasmid construct was delivered to 3-month-old $A b c c 6^{-1}$ mice by HTVI. The rapid injections (performed $<5$ seconds apart) were performed with a 27 -gauge needle with a volume of 1.5 to $2 \mathrm{~mL}$ of DNA in a solution of TransIT EE, according to the manufacturer's instruction (Mirus Bio). Mice were injected with 40 to $60 \mu \mathrm{g}$ of plasmid. Nine mice were injected with ABCC6 cDNA. Mice were euthanized by standard carbon dioxide procedures 24 hours after HTVI and immediately subjected to liver perfusion.

\section{Myocardial Cryoinjury}

At 72 hours after tail vein injection, cardiac injury was instilled through transdiaphragm cryoinjury, as previously described by one of us. ${ }^{30,31}$ Briefly, 10-second freeze-thaw injuries using a liquid nitrogen-cooled probe are applied to the heart through the diaphragm from a $10-$ to $12-\mathrm{mm}$ incision on the abdomen. This approach limits the area of cardiac injury to a single cardiac location and offers a relative uniform size of the necrotic tissue and a high survival rate $(>90 \%)$. Sham-operated $A b c c 6^{-1-}$ mice underwent the same surgical procedure using room temperature probe. Mice were sacrificed by carbon dioxide asphyxiation 7 days after injury to ensure that the cardiac calcification phenotype was fully developed. Hearts were quickly removed, rinsed in phosphate-buffered saline, minced, and placed into $0.15 \mathrm{~N} \mathrm{HCl}$ for 48 hours; then, calcium content of the supernatant was determined by a colorimetric assay (Calcium LiquiColor Test, Stanbio Laboratory, Boerne, TX).

\section{Histochemistry and Calcification Measurements}

Calcium deposition was directly visualized after Alizarin Red S staining on paraffin-embedded sections on the left 
muzzle skin of each mouse, as previously described. ${ }^{32}$ The level of mineralization in whiskers or hearts (minus the atria) was quantified following several methods. We first used the Calcium LiquiColor colorimetric assay (StanBio, Boerne, TX) ${ }^{33}$ that measures directly the amount of excess calcium, which is normalized to the weight of the excised tissues, as previously described, ${ }^{16}$ and expressed in $\mu \mathrm{g} / \mathrm{dL}$ per milligram of tissue. We also used two separate morphometric analyses of Alizarin Red S staining on histology sections. The ImageJ software version $1.45 \mathrm{k}(\mathrm{NIH}$, Bethesda, MD; http://imagej.nih.gov/ij) was used to measure the calcified area of each vibrissa (10 to 15 per section), which was then normalized to the area of the capsule, and averaged to provide an estimate of the extent of calcification of all vibrissae in a section. At least three sections per mouse were used. This analysis was confirmed using a second method of visual scoring of Alizarin Red S staining on histology sections with operators (J.Z., B.C., K.P.) blinded to the genotype and treatment.

\section{PPi and Bisphosphonate Administration}

$\mathrm{PPi}$, etidronate (Etd), and alendronate (Aln) were purchased from Sigma-Aldrich (St. Louis, MO) as tetrasodium decahydrate, disodium hydrate, and monosodium trihydrate salts, respectively. All dosages referenced thereafter are based on these sodium hydrated forms in which the PPi, Etd, and Aln fractions represent $39 \%, 74 \%$, and $76 \%$ of the molecular weight, respectively. Based on a previous study where rats were administered 80 to $160 \mu \mathrm{mol} / \mathrm{kg}$ per day of $\mathrm{PPi}^{22}$ we chose to use a wider range of 2.24 to $224 \mu \mathrm{mol} / \mathrm{kg}$ per day (equivalent to 1 to $100 \mathrm{mg} / \mathrm{kg}$ per day) of PPi in a volume of $100 \mu \mathrm{L}$ of saline $(0.9 \% \mathrm{NaCl})$ solution on mice via i.p. injection. Injections were initiated 24 hours before induction of DCC via cryoinjury and daily thereafter until euthanasia. Control animals received injections of saline. For the experimental groups of mice testing the effect of PPi on chronic calcification, the animals were weighed every week, and the volume injected was adjusted accordingly. For control experiments, groups of mice were treated in parallel with saline injections. Etd and Aln were delivered via i.p. injection in $100 \mu \mathrm{L}$ volume starting with a single injection of $8 \mu \mathrm{mol} / \mathrm{kg}$ per day (Etd) or $0.062 \mu \mathrm{mol} / \mathrm{kg}$ per day (Aln) 6 hours before DCC induction (equivalent to 2.0 and $0.02 \mathrm{mg} / \mathrm{kg}$ per day, respectively). Mice received two additional doses of Etd or Aln on days 2 and 3. Cardiac tissues were harvested at day 7 after injury, as described previously. ${ }^{34}$ The Etd dosage chosen was $10 \%$ of the typical oral amount given for Paget disease of bone $(80 \mu \mathrm{mol} / \mathrm{kg}$ per day or $20 \mathrm{mg} / \mathrm{kg}$ per day) and similar to a previous study $^{35}$ considering a bioavailability of $1 \%$ to $3 \%$. Human dosages of Aln vary depending on the application and it has an oral bioavailability of approximately $0.5 \%$. Therefore, we chose to administer $0.062 \mu \mathrm{mol} / \mathrm{kg}$ per day $(0.02 \mathrm{mg} / \mathrm{kg}$ per day) of Aln, based on the dosage used in a previous report. ${ }^{18}$

\section{Liver Perfusion}

Liver perfusions were performed on anesthetized mice via the cannulation of the hepatic portal vein and inferior vena cava. Livers were initially flushed with a perfusion buffer $\left(1 \times \mathrm{Krebs}, 1 \times \mathrm{HEPES}, 24 \mathrm{mmol} / \mathrm{L} \mathrm{NaHCO}{ }_{3}, 1.3 \mathrm{mmol} / \mathrm{L}\right.$ $\mathrm{CaCl}_{2}, 0.1 \%$ bovine serum albumin) to remove blood and the same buffer batch was used on all mice. The perfusion flow was set at $1.0 \mathrm{~mL} /$ minute for up to 15 minutes, and four equal aliquots were collected. The perfusates were stored at $-80^{\circ} \mathrm{C}$ before analysis.

\section{Pyrophosphate, Alkaline Phosphatase, and ATP Measurements}

The concentration of PPi in plasma or liver perfusate was calculated, as described previously, ${ }^{8}$ by one of us (K.v.d.W.). Plasma was collected from 3-month-old mice unless stated otherwise. When investigating the effect of human ABCC6 expression on PPi secretion in liver, perfusions were performed 24 hours after hydrodynamic tail vein injections. PPi concentration in liver perfusion buffer was measured in all four aliquots individually, and the data were averaged. There was no major fluctuation in PPi concentration in the different aliquots over this 15-minute period of time. The PPi concentration of the perfusion buffer before perfusion was also measured, and it was found to be negligible $(0.5$ to $1 \mu \mathrm{mol} / \mathrm{L}$ compared to 200 to 600 $\mu \mathrm{mol} / \mathrm{L}$ after perfusion). Alkaline phosphatase activity was measured in plasma samples of wild-type and $A b c c 6^{-1-}$ mice using a colorimetric assay kit (Biovision, Milnitas, CA). The kit uses $p$-nitrophenyl phosphate as substrate, which is converted into colored $p$-nitrophenyl measured by optic density at $405 \mathrm{~nm}$. Units of alkaline phosphatase activity correspond to $\mu \mathrm{mol}$ of $p$-nitrophenyl $/ \mathrm{mL}$ per minute. ATP was measured in perfusion samples, as previously described, ${ }^{7}$ and in plasma using the BacTiter-Glo Microbial Cell Viability Assay from Promega (Madison, WI).

\section{Transgenic Mice}

\section{PiggyBac Delivery Plasmid Development}

A cDNA encoding the normal human $\mathrm{ABCC} 6^{27}$ and a PXE/ GACI-causing mutant ABCC6 cDNA $^{12,36}$ were cloned into piggyBac delivery plasmids used for transgenic animal production. Expression of the piggyBac transposase from these plasmids allowed the efficient integration of transgenes into the genome of newborn mice. ${ }^{37,38}$ In an effort to achieve liver-specific expression of the $A B C C 6 \mathrm{cDNA}$, we used the ZY53 promoter previously described. ${ }^{39,40}$ This promoter and coding sequences for the wild-type and R1314W mutant of ABCC6 were first cloned into pENTR1a shuttle plasmids to prepare for Gateway recombineering 
(Invitrogen, Carlsbad, CA). These two shuttle plasmids were each recombined into the pmhyGENIE-3 piggyBac delivery plasmid. The resulting plasmids, pmhyGENIE-3ABCC6 and pmhyGENIE-3-ABCC6-R1314W, encoded the respective $A B C C 6$ transgene, TurboGFP, and a selfinactivating ${ }^{37,38}$ hyperactive piggyBac transposase ${ }^{41}$ driven by the CAG (cytomegalovirus immediate early enhancer, chicken $\beta$-actin promoter, and $\beta$-globin intron) promoter.

Transposase-Enhanced Pronuclear Microinjection and Cytoplasmic Microinjections with pmGENIE Plasmids Plasmid vectors, pmhyGENIE-3-ABCC6 and pmhyGENIE3-ABCC6-R1314W, were injected directly into the pronu-

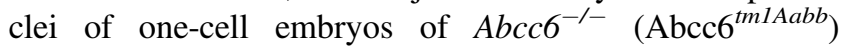
zygotes using a $2-\mu \mathrm{m}$ internal diameter, modified, bluntended microinjection pipette using a Piezo actuator. The process is designated transposase-enhanced pronuclear microinjection. The injected volume was calculated with the following equation: $\pi . \mathrm{r} 2$ length.

An injection of $65 \mu \mathrm{m}$ equals $2.04 \times 10^{-7} \mu \mathrm{L}$. At a concentration of $10 \mathrm{ng} / \mu \mathrm{L}$ of plasmid solution, the total amount of DNA injected is $2.04 \mathrm{fg}$ or approximately 130 copies of plasmid.

The presence of the transgenes was verified by PCR using primers specific to the construct and sequencing. The transgene copy number in each mouse was determined using two TaqMan Copy Number Assays (hs00025196_cn, hs0003881_cn) for redundancy and the mouse reference gene Tfrc. The copy number assays were performed on an Applied Biosystems (Foster City, CA) StepOnePlus RealTime PCR machine and the included CopyCaller Software version 2.0 (Applied Biosystems).

\section{Embryo Culture and Embryo Transfer}

Oocytes with two well-developed pronuclei and a distinct second polar body 5 to 6 hours after transposase-enhanced pronuclear microinjection were recorded as having survived microinjection and were cultured in CZB medium (Millipore, Billerica, MA) until two-cell stage (20 to 24 hours after microinjection). They were then transferred into the oviducts of surrogate CD-1 females, which were mated with vasectomized males of the same strain on the day before embryo transfer. Pregnant females were allowed to deliver and raise their pups.

\section{RT-PCR}

We used real-time PCR to determine the level of mRNA expression for the human ABCC6. Total RNA was extracted from approximately $20 \mathrm{mg}$ of tissue sample using the RNeasy kit (Qiagen Inc., Valencia, VA). The RNA was converted into first-strand cDNA using a first-strand synthesis kit with random hexamers (Thermofisher Scientific, Waltham, MA). The level of expression of the human $A B C C 6$ and the mouse ENPPI and GAPDH was detected by quantitative RT-PCR with a StepOnePlus Real-Time
System (Applied Biosystems, Foster City, CA) using commercially available TaqMan probes.

\section{Immunodetection}

Liver-specific expression of ABCC6 variants in mice and immunohistochemical staining were performed as described in a previous study ${ }^{27}$ Briefly, after mouse euthanasia, multiple liver lobes were quickly harvested, placed in OCT compound, and stored at $-80^{\circ} \mathrm{C}$. Immunofluorescence staining was performed on frozen sections ( $6 \mu \mathrm{m}$ thick). The rat monoclonal anti-ABCC6 M6II-31 antibody (sc-59618; Santa Cruz Biotechnology, Dallas, TX) was used to specifically detect the human ABCC6. The rabbit polyclonal anti-cadherin antibody was purchased from Abcam (Cambridge, MA). The secondary antibodies were Alexafluor 488 and 568 (Life Technologies, Carlsbad, CA). Immunofluorescence images were acquired using an Axioscope 2 fluorescent microscope (Zeiss, Thornwood, NY). Individual images were collected and processed with Photoshop CS6 (Adobe, San Jose, CA).

\section{Statistical Analysis}

Data were compared by the $t$-test. Values are expressed as means \pm SEM. $P<0.05$ was considered statistically significant. Animal numbers used for individual sets of data varied and are shown in the figures.

\section{Results}

ABCC6 Regulates the Majority of PPi Release from the Liver

The recent findings of Jansen et al ${ }^{7,8}$ revealed that ABCC6 mediates the cellular release of ATP, which is quickly converted into PPi. In their study, the authors suggested that ABCC6 function in liver is an important contributor to plasma PPi. Therefore, we directly measured the levels of ATP and PPi released by the liver of wild-type, $A b c c 6^{-/-}$, and $A b c c \sigma^{-/-}$mice transiently expressing the human ABCC6. Using this in vivo liver perfusion, ATP was lower than detection level in all samples (data not shown), as expected because ectonucleotidases (ENPP1) would convert it rapidly. ${ }^{8}$ We also measured a two-thirds reduction in PPi average concentration in liver perfusates of $A b c c 6^{-1-}$ mice compared to wild-type controls $(627 \pm 96 \mathrm{nmol} / \mathrm{L}$ versus $221 \pm 55 \mathrm{nmol} / \mathrm{L} ; P=0.0003$ ) (Figure $1 \mathrm{~A}$ ). Strikingly, introducing human ABCC6 in the liver of $A b c c 6^{-1-}$ mice via HTVI 24 hours before liver perfusion increased the PPi concentration in liver perfusate to near normal levels $(77 \%$ of wild-type levels; $482 \pm 85 \mathrm{nmol} / \mathrm{L}$ versus $627 \pm 96$ $\mathrm{nmol} / \mathrm{L} ; P=0.26$ ), despite the modest levels of expression achieved with hydrodynamic tail vein injections. ${ }^{16,27}$ For control purposes, we also measured ATP levels in the plasma of wild-type and $A b c c 6^{-1-}$ mice and found no significant differences in steady-state levels $[1.58 \pm 0.36$ 
A

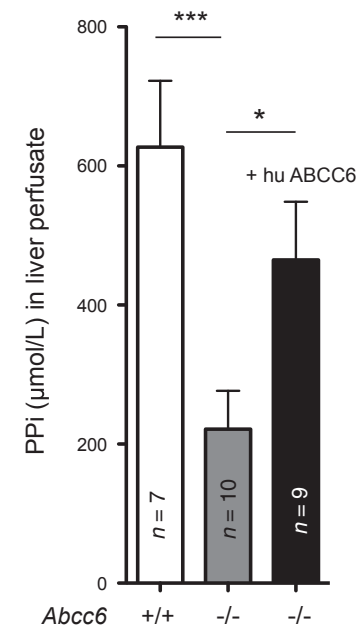

D

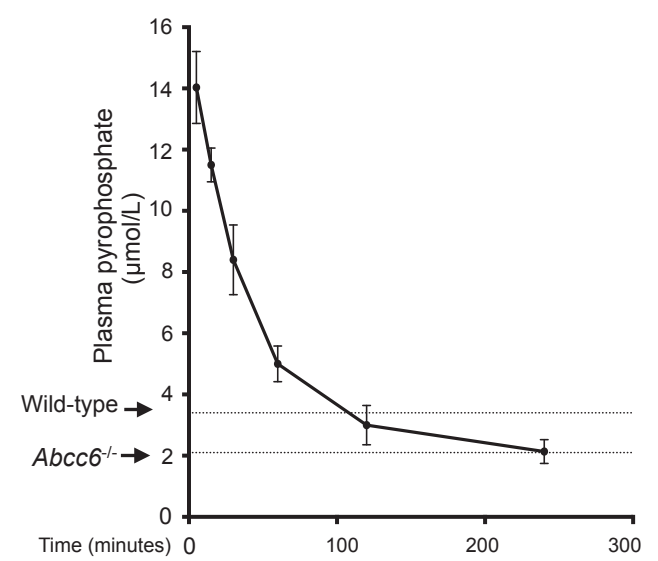

B

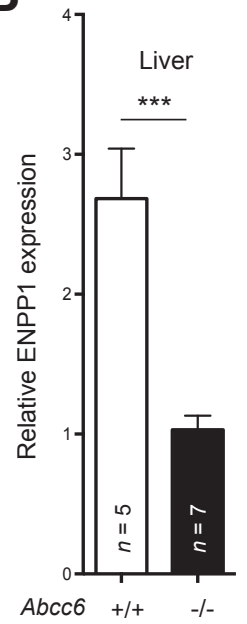

$\mathbf{E}$

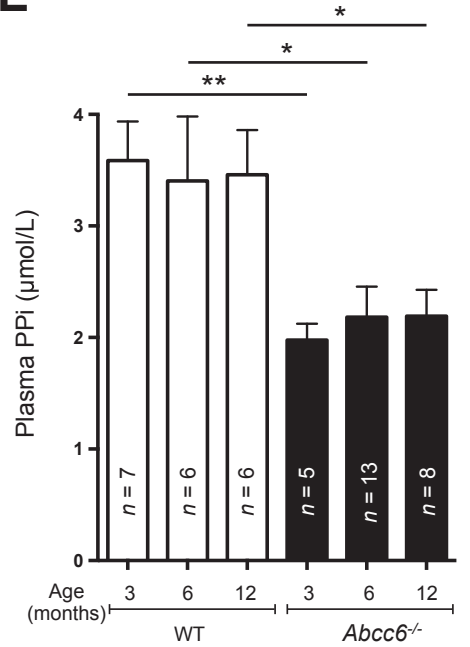

C

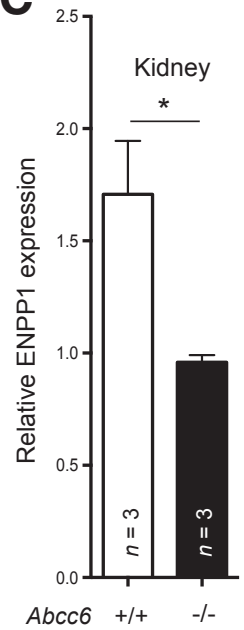

$\mathbf{F}$

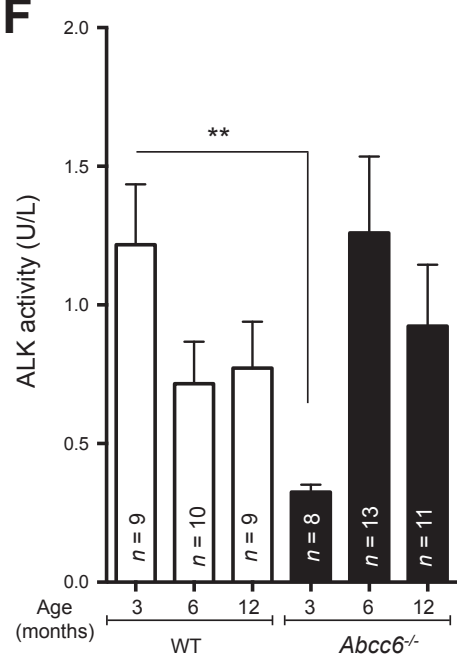

Figure 1 Pyrophosphate $(\mathrm{PPi})$ and bisphosphonates. A: The generation of ABCC6-dependent hepatic PPi was estimated in liver perfusate. The concentration of $\mathrm{PPi}$ in the perfusate buffer was compared between wild-type (WT; $+/+$ ) and $A b c c 6^{-/-}$mice $(-/-)$, and to $A b c c \sigma^{-/-}$mice transiently expressing the human ABCC6 in liver. The relative level of expression of ENPP1 in the liver (B) and kidneys (C) of $A b c c 6^{-/-}$mice and wild-type mice was determined by real-time PCR using specific TaqMan probes. The data were normalized to the mouse GAPDH. D: PPi plasma concentration steadily decreases after a single i.p. injection of PPi at $112 \mu \mathrm{mol} / \mathrm{kg}(50 \mathrm{mg} / \mathrm{kg})$ in $A b c c \sigma^{-1-}$ mice with an approximate half-life of 42 minutes. Average plasma PPi levels of wild-type and $A b c c 6^{-/-}$mice are indicated. E: Plasma PPi concentration was significantly reduced in $A b c c 6^{-/-}$mice at 3-, 6-, and 12-month-old mice. At each time point, PPi levels were significantly lower in $A b c c \sigma^{-/-}$mice, though age does not influence PPi levels in either wild-type $(+/+)$or $A b c c \sigma^{-/-}$ mice (-/-). F: Alkaline phosphatase activity (ALK) expressed as units ( $\mu$ mol of $p$-nitrophenyl/L per minute) was measured in plasma samples from the same $3-, 6-$, and 12 -month-old wild-type $(+/+)$ and $A b c c 6^{-/-}$mice $(-/-)$as shown in $\mathbf{E}$. The number of mice per group is shown. Data are expressed as means \pm SEM. $n=3$ per data point (D). ${ }^{*} P<0.05,{ }^{* *} P<0.01$, and ${ }^{* * *} P<0.001$.

$\mathrm{nmol} / \mathrm{L}(n=16)$ versus $2.30 \pm 0.36 \mathrm{nmol} / \mathrm{L}(n=18)$ $P=0.17$, respectively]. Because Jansen et al ${ }^{7,8}$ suggested that ABCC6 is upstream of ENPP1 and provides its substrate (ATP), we investigated its gene expression levels in both liver and kidneys. Our results showed a significant decrease of Enppl expression in both organs of $A b c c 6^{-1-}$ mice as compared to wild type (Figure 1, B and C).

\section{PPi Administration}

Because one of the primary objectives of this study was to evaluate the effects of PPi supplementation on the acute and chronic calcification phenotypes of $A b c c 6^{-1-}$ mice, we first performed a pharmacokinetic study of PPi in the circulation after i.p. delivery. Indeed, $A B C C 6$ knockdown causes an increase of TNAP in an in vitro model, ${ }^{42}$ and there was a possibility that this could also happen in vivo and affect PPi clearance in mice. We found that a $112 \mu \mathrm{mol} / \mathrm{kg}(50 \mathrm{mg} / \mathrm{kg})$ injection produced after 5 minutes a plasma concentration of approximately $14 \mu \mathrm{mol} / \mathrm{L}$, which corresponds to a bioavailability of approximately $0.5 \%$. This concentration decreased to $A b c c 6^{-1-}$ mice levels (approximately 2.1 $\mu \mathrm{mol} / \mathrm{L})$ in approximately 4 hours. From these data, we estimated a half-life of plasma PPi of 42 minutes 


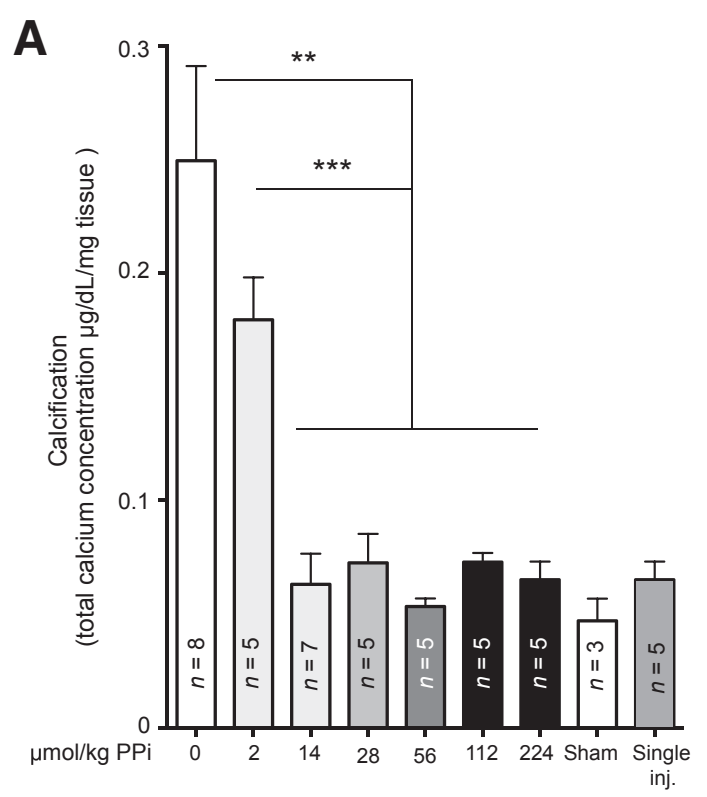

(Figure 1D) in $A b c c 6^{-1-}$ mice, which is similar to that found in previous studies with wild-type rats and other $A b c c 6^{-1-}$ mice. ${ }^{7,22}$ Moreover, we tested whether plasma PPi concentration fluctuated in wild-type and $A b c c 6^{-/-}$mice with age, which could potentially influence long-term PPi supplementation. We found no major variation in both wild-type and $A b c c 6^{-1-}$ mice, over a 1 -year period (Figure 1E). Surprisingly, alkaline phosphatase activity in the plasma of 3-month-old $A b c c 6^{-1-}$ mice was much lower than their wild-type counterpart $(0.32 \pm 0.03 \mathrm{U} / \mathrm{L}$ versus $1.217 \pm 0.22$ $\mathrm{U} / \mathrm{L} ; P=0.0016$ ), although there was no significant difference between older age groups (Figure 1F).

\section{Effects of PPi on the Acute Calcification Phenotype (DCC)}

It was previously established that a physical or ischemic injury to the myocardium of $A b c c 6^{-/-}$mice triggers the rapid development-within 3 days-of DCC. ${ }^{30}$ This acute calcification phenotype is largely controlled by the level of hepatic ABCC6 expression. ${ }^{16}$ Therefore, we tested whether PPi supplementation can influence the development of DCC. We performed a dose response study in $A b c c \sigma^{-1-}$ mice using a PPi concentration range from 2.24 to 224 $\mu \mathrm{mol} / \mathrm{kg}$ (1 to $100 \mathrm{mg} / \mathrm{kg}$ ) via single daily i.p. injections of $100 \mu \mathrm{L}$ for 7 days after cardiac cryoinjury. This myocardial injury was instilled on 6-week-old mice through the well-established transdiaphragm freeze-thaw method. PPi injections completely inhibited DCC (Figure 2A), as determined by the measure of excess cardiac calcium. The minimal effective dose was between 2.24 and $13.44 \mu \mathrm{mol} /$ $\mathrm{kg}$ ( 1 and $6 \mathrm{mg} / \mathrm{kg}$ ). Interestingly, we found that a single i.p. injection of PPi of $28 \mu \mathrm{mol} / \mathrm{kg}(12.5 \mathrm{mg} / \mathrm{kg})$ within 30 minutes after the initial cardiac injury was sufficient to inhibit the development of DCC (Figure 2A).
Effects of Bisphosphonates on the Acute Calcification Phenotype (DCC)

Bisphosphonates are inorganic pyrophosphate analogs with anti-osteoclastic and/or anti-mineralization properties that stem from their ability to bind calcium and enzymes that use $\mathrm{PPi}^{43}$ There are two main categories of bisphosphonates, non-nitrogen containing, such as etidronate, and nitrogen containing, such as alendronate. The effects of these two types of bisphosphonates have never been tested against the acute DCC phenotype. Ten-week-old $A b c c 6^{-/-}$mice were used for this experiment. Mice were subjected to freezethaw cardiac injury just 1 day after bisphosphonate administration. No animal died prematurely in the course of these experiments. The i.p. injections of bisphosphonate did not cause obvious distress from possible toxicity. After harvesting hearts 7 days after injury, we found that etidronate treatment nearly abolished cardiac calcification $(0.28 \pm 0.03$ $\mu \mathrm{g} / \mathrm{dL}$ per $\mathrm{mg}$ versus $0.03 \pm 0.0203 \mu \mathrm{g} / \mathrm{dL}$ per $\mathrm{mg}$; $P=0.001)$ in $A b c c 6^{-1-}$ mice, whereas the administration of alendronate did not provide any significant attenuation of DCC as compared to control mice $(0.28 \pm 0.0303 \mu \mathrm{g} / \mathrm{dL}$ per $\mathrm{mg}$ versus $0.25 \pm 0.0303 \mu \mathrm{g} / \mathrm{dL}$ per $\mathrm{mg} ; P=0.51)$ (Figure 2B).

\section{The Effect of PPi Supplementation on Chronic Calcification}

Although the DCC phenotype in mice is ABCC6 depen$\operatorname{dent}^{6,15}$ and a useful marker of its physiological function, ${ }^{16}$ the chronic calcification of muzzle skin, in which the capsule of the vibrissae is affected, ${ }^{44}$ is the accepted analog of the human chronic PXE phenotype. ${ }^{45}$ In this series of experiments, we aimed to discover whether the provision of daily supplementation of PPi could compensate the negative 
effects of the Abcc6 knockout on both the development and progression of vibrissae mineralization. The first signs of mineralization in $A b c c \sigma^{-1-}$ mice are detectable in the capsule of the vibrissae at approximately 6 weeks of age. ${ }^{46}$ In a previous study, we quantified the development of vibrissae mineralization over the life span of $A b c c 6^{-1-}$ mice. ${ }^{32}$ This work notably established that vibrissae calcification increased rapidly within the first 6 months of age and slows thereafter, reaching a plateau in 12-month-old mice. Therefore, to test if PPi treatments could prevent the development of calcification, one-month-old mice (preonset) were subjected to daily PPi supplementation (224 $\mu \mathrm{mol} / \mathrm{kg}$ or $100 \mathrm{mg} / \mathrm{kg}$ ) for a period of 4 months up to the age of 5 months. Similarly, 6-month-old mice (postonset) received daily PPi injections for 5 months to determine whether the progression of established calcification could be blocked and/or reversed. For control purposes, age-matched $A b c c 6^{-1-}$ mice were administered a solution of saline for the same period of time.

To minimize harm to animals from repeated injection, we varied the site of injection to avoid repeated punctures in the same areas. We noticed that mice injected with PPi tended to display a discoloration of the fur at or near the site of injections. However, we noted no other overt adverse effects in behavior or gross anatomy, including obvious osseous abnormality after dissection in either control or experimental animals during and after treatment. Therefore, no mice were excluded from any treatment group. Unlike another study, ${ }^{22}$ we did not observe obvious signs of peritoneal inflammation. However, we observed some crystal deposits on the diaphragm of approximately one-third of the PPi-treated mice, which could be calcium pyrophosphate dehydrate (data not shown). In each group, calcification was assessed by direct measurement of excess calcium from the right side whisker of a mouse, and Alizarin Red S staining on the left side whisker. We found that daily PPi injection to preonset (1-month-old) $A b c c 6^{-/-}$mice for 4 months resulted in whisker calcification comparable to that found in 6-monthold wild-type animals $(P=0.31)$, whereas calcium levels in $A b c c 6^{-/-}$mice receiving saline injections had doubled in the same period of time $(P=0.0006)$ (Figure 3$)$. For the postonset group of mice (6 months old) that received an identical treatment for 5 months, calcification levels were half of that found in the saline controls $(P=0.0009)$, and these were also significantly lower than in untreated 6-month-old mice (Figure 3). The histological Alizarin Red S stain of the vibrissae revealed only minimal traces in the capsules of the preonset group that received PPi injections (Figure 4A). The morphometric analysis of the calcified areas was consistent with the direct measurements of the calcium content of the whiskers (Figure 4B). The animals in the postonset group treated with PPi had visibly less mineralized vibrissae capsules than the saline controls at the same age or 6-month-old untreated mice (Figure 4, A and C). Renal calcification, which develops slower and is minimal in comparison to vibrissae in $A b c c 6^{-/-}$mice in the first year of

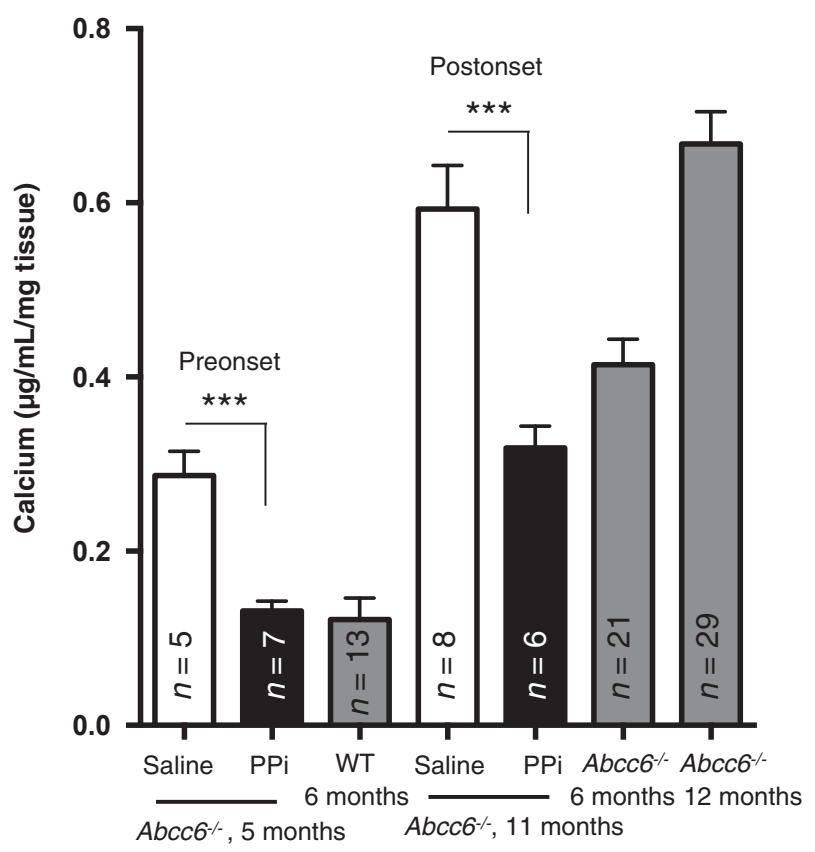

Figure 3 The effect of pyrophosphate (PPi) on the chronic (pseudoxanthoma elasticum-like) calcification phenotype of $\mathrm{Abcc}^{-/-}$mice. $A b c c 6^{-1-}$ mice were injected daily for 16 to 20 weeks with either saline (white bars) or a PPi solution at $224 \mu \mathrm{mol} / \mathrm{kg}$ per day (eg, $100 \mathrm{mg} / \mathrm{kg}$ per day) (black bars). Injections started either at weaning before the onset of ectopic calcification in vibrissae and continued daily for 16 weeks or were initiated at 6 months of age (after onset) when whiskers calcification is well developed, and continued for 20 weeks. For comparison purposes, vibrissae calcification of untreated $A b c c \sigma^{-/-}$mice is shown (gray bars). The number of mice per group is shown. Data are expressed as means \pm SEM. $* * * P<0.001$. WT, wild-type.

life, was also quantified in preonset and postonset groups. There was no significant variation between treated and control mice in the preonset group and a minor yet significant difference $(-40 \%)$ was found in the postonset group of mice (Supplemental Figure S1).

\section{The Effect of a Human ABCC6 Transgene on the Phenotype of $\mathrm{Abcc \sigma}^{-/-}$Mice}

In previous studies, ${ }^{16,47}$ we have shown that the transient expression of a human ABCC6 cDNA specifically in $A b c c 6^{-/}$mouse liver had a significant inhibitory effect on the acute, short-term DCC phenotype. To test whether permanent ABCC6 expression in $A b c c 6^{-/-}$mouse liver affected the long-term chronic calcification phenotype in $A b c c 6^{-/-}$mice, we generated transgenic lines of $A b c c 6^{-/-}$ mice, expressing the normal human ABCC6 protein and a PXE/GACI-causing ABCC6 mutant (R1314W) for control purposes. As Jansen et $\mathrm{al}^{7}$ suggested that ABCC6 function in liver is an important contributor to plasma PPi, we sought to express the human ABCC6 primarily in hepatocytes by using a previously characterized liver-specific promoter. ${ }^{39,40}$ The transposase-enhanced pronuclear injection resulted in $25 \%$ success rate. Of these animals, $52 \%$ carried two copies 
A

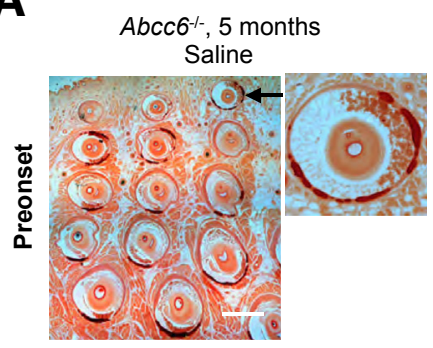

$A b c c 6^{-1-}, 5$ months $\mathrm{PPi}$

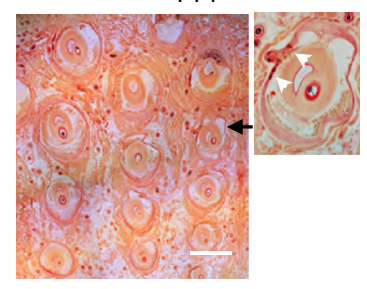

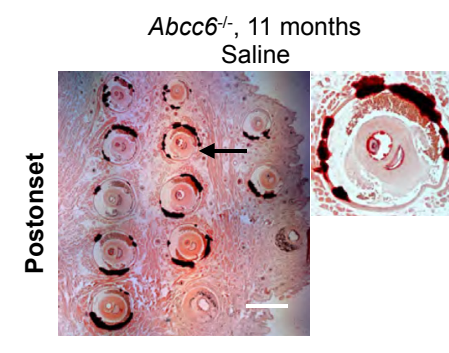

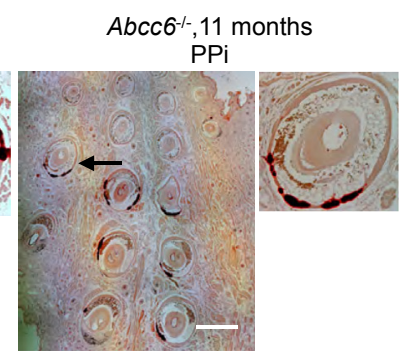

\section{B}

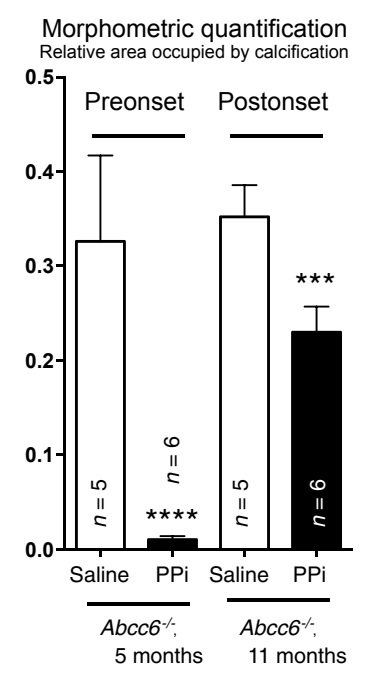

\section{C}

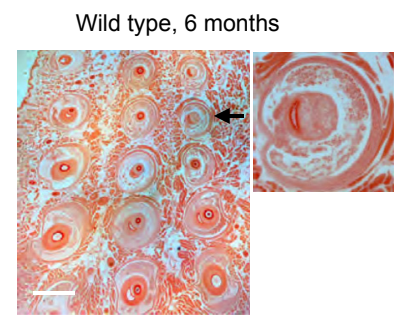

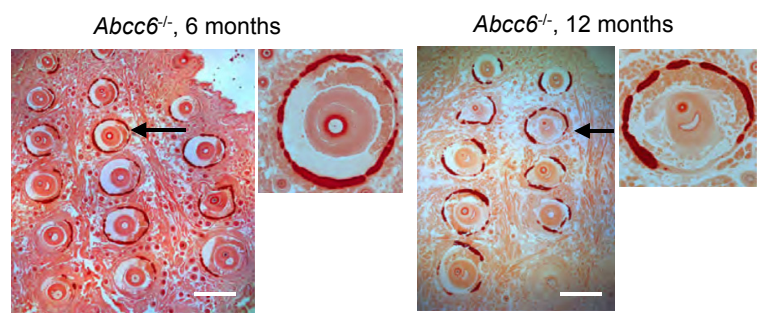

Figure 4 Histological evaluation of vibrissae calcification of $A b c c 6^{-/-}$mice after pyrophosphate (PPi) supplementation. The effect of daily PPi or saline injections on the calcification of vibrissae (chronic pseudoxanthoma elasticum-like phenotype) of $A b c c \sigma^{-/-}$mice was evaluated by Alizarin $S$ Red staining (red to dark red color). A: Representative images of whiskers with approximately 15 vibrissae are shown for the preonset and postonset treatment groups with saline controls. A higher magnification image of a selected vibrissa (arrows) is shown. Arrowheads point to discrete calcification. B: The relative area occupied by calcification, as visualized by Alizarin red staining, was also quantified by morphometric analysis using the ImageJ software and show significant reduction between the saline and PPi treatments. C: For comparison purposes, representative images of whiskers from untreated $A b c c 6^{-/-}$mice are included. A higher magnification image of a selected vibrissa (arrows) is shown. The number of mice per group is shown. Data are expressed as means $\pm \mathrm{SEM}$. ${ }^{* *} P<0.001$, ${ }^{* * * *} P<0.0001$ versus saline. Scale bars $=500 \mu \mathrm{m}$ (A and C). Original magnification, $\times 200$ (higher magnification images).

of the transgenes, $27 \%$ carried three or more copies (up to six), and $17 \%$ harbored only one copy. Transgenic pups were initially selected using fluorescence from a green fluorescent protein reporter gene (transcribed in reverse orientation) ubiquitously expressed under the control of a cytomegalovirus promoter. Of the green fluorescent protein-positive mice, $6 \%$ did not carry the human ABCC6 cDNA and were excluded from this study.

Unexpectedly, the expression of both transgenes (wildtype and mutant ABCC6) was relatively low and heterogeneous. The liver expression was modest as compared to the human ABCC6 transiently expressed via HTVI (Figure 5A); however, the human protein was clearly detectable in the plasma membrane of hepatocytes (Figure 5B). The ABCC6 mRNA was also detected at low levels in various tissues, such as the aorta, intestine, heart, lungs, spleen, and eyes (data not shown). The reason for this heterogeneous expression and the partial silencing of the transgenes is unclear, but the number of transgene copy did not seem to correlate with PPi levels or the calcification phenotype.

Despite the relatively low expression of the wild-type $A B C C 6$ transgene, we measured a significant increase in plasma PPi $(27 \%, P=0.0085)$ as compared to $A b c c 6$ knockout controls. Plasma PPi levels did not change significantly in mice carrying the $\mathrm{R} 1314 \mathrm{~W}$ mutant transgene (Figure 6A). Interestingly, age had no significant influence on PPi concentration in the circulation of the transgenic animals (data not shown). Consequently, we first verified whether this increase in circulating $\mathrm{PPi}$ associated with the wild-type ABCC6 transgene had an effect on DCC phenotype. We found that the development of DCC was dramatically reduced when compared to $A b c c 6^{-/-}$controls $(-92 \%$, $P=0.0005$ ), and that the cardiac calcium levels were on par with these of $A b c c 6^{-1-}$ sham-operated animals (Figure 6B). Of note, the relatively low level (Figure 5A) but continuous expression of the wild-type $A B C C 6$ transgene provided a better protection against DCC than higher level of transient 


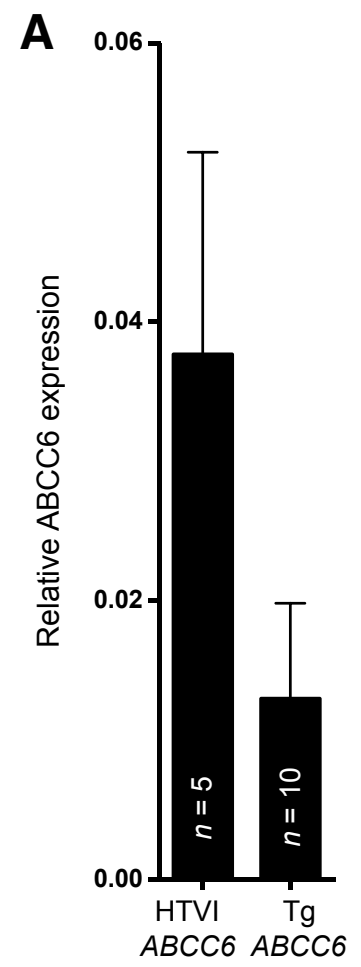

B
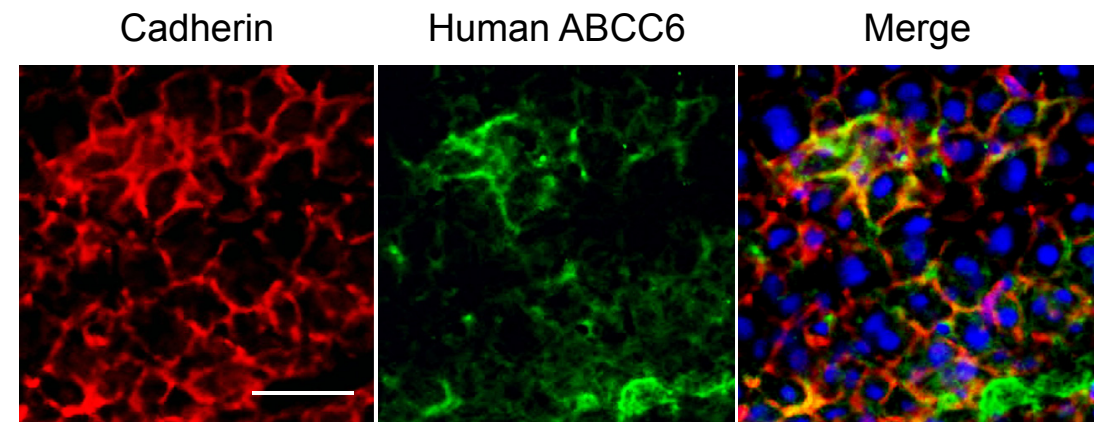

M6II-31

Figure 5 The human $A B C C 6$ transgene is expressed at low but detectable levels in liver. A: The level of expression of normal human $A B C C 6$ in the liver of $A b c c 6^{-1-}$ transgenic mice ( $\left.\operatorname{Tg} A B C C 6\right)$ was determined by real-time PCR using TaqMan probes specific to the human $A B C C 6$ and the mouse GAPDH and compared to the transient expression of the same human ABCC6 obtained by hydrodynamic tail vein injections (HTVIs; ABCC6). B: Frozen sections of livers from $A b c c \sigma^{-/-}$ transgenic mice carrying the human $A B C C 6$ cDNA were used to perform immunofluorescence colabeling of the human ABCC6 (green, using the M6II-31 monoclonal antibody) and the plasma membrane marker cadherin (red). DAPI was used as counter staining (blue). Scale bar $=100 \mu \mathrm{m}(\mathbf{B})$.

expression in $A b c c 6^{-/-}$mice $(0.025 \pm 0.002$ versus $0.065 \pm 0.016 ; P=0.017$ ). As an additional control, we verified that the transient expression of an unrelated gene (LacZ) did not inhibit cardiac calcification.

Furthermore, we examined over a period of 18 months the effect of the ABCC6 transgenes on the chronic phenotype. We found that the calcium levels in the vibrissae were undistinguishable from wild-type levels during the first 12 months and started increasing at 18 months (Figure 6C). Surprisingly, the R1314W mutant transgene also had a significant inhibitory effect on the calcification of vibrissae (especially at 3 months), with mineralization progressively increasing to levels similar to $A b c c 6^{-/-}$control mice only at 18 months. We also evaluated the transgene effects on renal calcification, which develops later and is less pronounced than in vibrissae. We found a complete regression of renal calcification with wild-type $A B C C 6$ transgene, but there was no significant effect from the R1314W mutant transgene with a progression that mirrors that of the $A b c c 6^{-1-}$ control mice (Figure $6 \mathrm{D}$ ). These results were confirmed by histological staining with Alizarin Red, showing a considerable delay in the onset and progression of calcification in vibrissae. There was no detectable calcification in mice with the wild-type transgene at 3 months, and hardly any mineralization at 6 and 12 months as the whiskers were sectioned through entirely. Only minor hydroxyapatite deposits were found at 18 months (Figure 7A). Histological evaluation of whiskers from R1314W transgenic mice revealed some evidence of nascent calcification at 3 months and more noticeable mineralization at 6 months. Calcification was more pronounced at 12 months and fully developed at 18 months of age (Figure $7 \mathrm{~B}$ ).

\section{Discussion}

In this study, we have demonstrated that supplementation with PPi and the nonhydrolyzable analog etidronate effectively prevents the development of acute and chronic calcification in a mouse model for PXE. PPi is the main systemic inhibitor of ectopic calcification, and its normal plasma concentration is in the micromolar range both in rodent models and humans. ${ }^{21,48}$ The role of the liver in PPi release has been suggested before, ${ }^{49}$ and the recent report of Jansen et $\mathrm{al}^{7}$ has provided substantial evidence in this regard. Our data from $A b c c 6^{-1-}$ mice transiently expressing human ABCC6 protein in liver (Figure 1) and the effect of $A b c c 6$ deficiency on ENPP1 expression have now confirmed their results and expanded on this conclusion that ABCC6 is acting

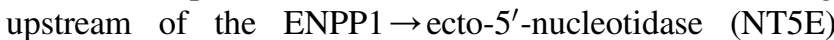
pathway (Figure 8). Indeed, ABCC6 has a direct and significant contribution to circulating PPi levels, and the downregulation of ENPPI suggests a negative feedback mechanism that contributes to and/or aggravates PPi deficits. 
A

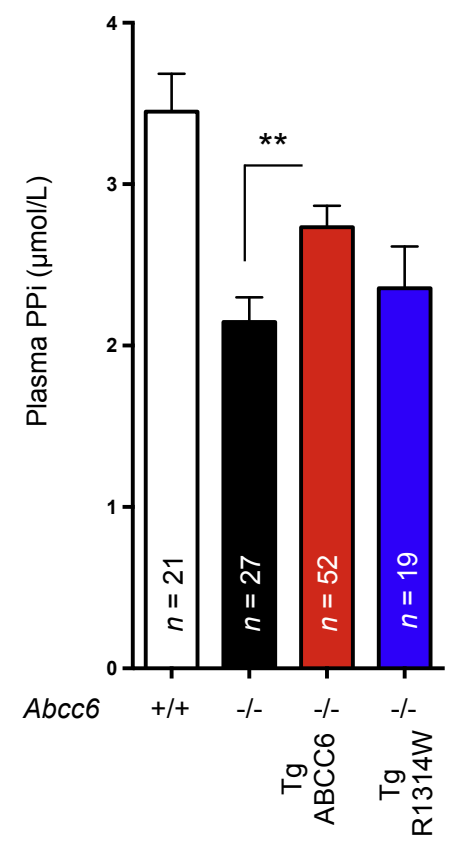

C

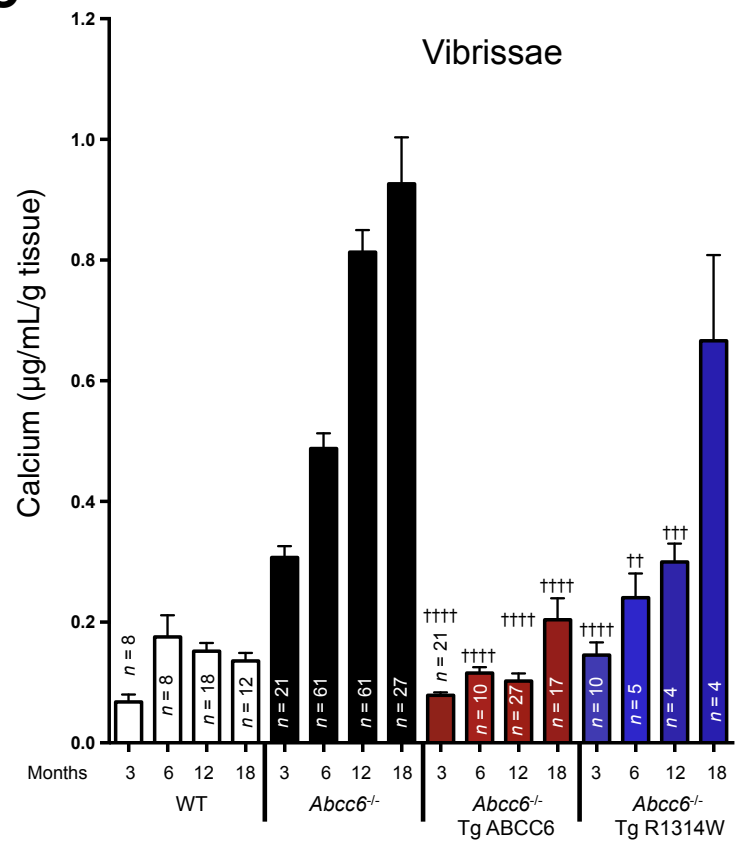

B

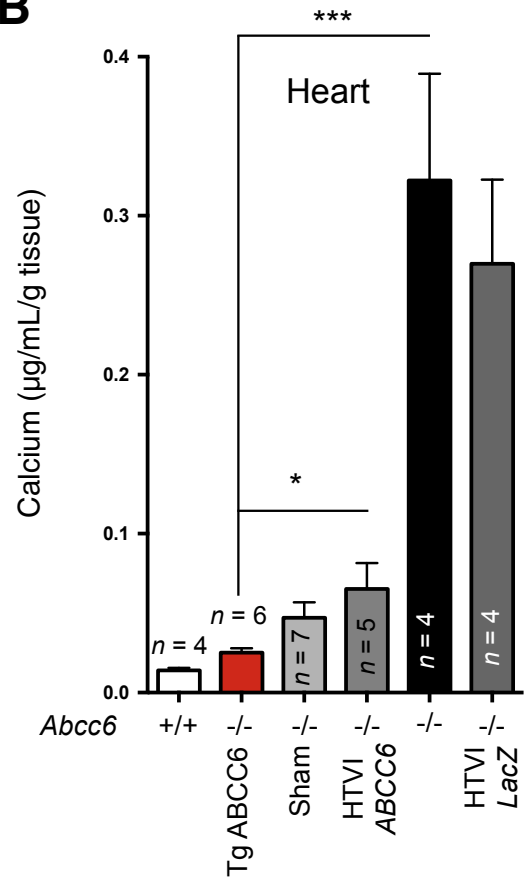

D

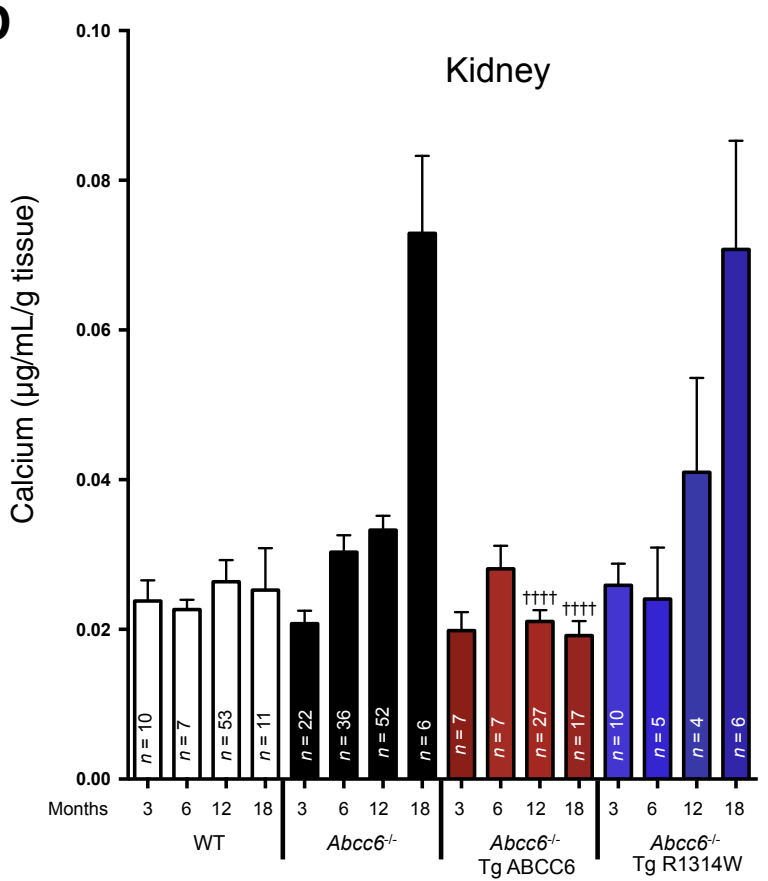

Figure 6 Effects of the human wild-type (WT) $A B C C 6$ and R1314W variant transgenes on the phenotype of $A b c c \sigma^{-/-}$mice. A: The plasma pyrophosphate (PPi) concentration in transgenic mice carrying the wild-type $A B C C 6$ (Tg ABCC6) is significantly higher (27\%) over the nontransgenic $A_{b c c 6^{-1-}}$ control mice, whereas there is no statistically significant difference with R1314W transgenics (Tg R1314W). B: The effects of the wild-type $A B C C 6$ transgene on dystrophic cardiac calcification (DCC) was tested in 3- to 5-month-old mice ( $\operatorname{Tg} A B C C 6)$. The level of calcification was measured as total ventricular calcium. For control purposes, the results are compared to calcification in wild-type, $A b c c \sigma^{-/-}$mice and knockout animals transiently expressing the human $A B C C 6$ or the LacZ CDNA [hydrodynamic tail vein injection (HTVI)] after cryoinjury. Sham-operated $A b c c 6^{-/-}$mice were also used as controls. The DCC phenotype is significantly reduced in the Tg animals. The effects of the human wild-type ABCC6 and R1314W variant transgenes on chronic calcification in vibrissae (C) and kidneys (D) was determined over a period of 18 months. Calcification levels are shown for wild-type mice, $A b c c 6^{-1-}$ mice, $A b c c 6^{-1-}$ mice with the human $A B C C 6$ transgene, or the R1314W variant transgene. Note that the $y$ axis scale for the kidney calcification data are approximately $8 \%$ of the vibrissae. The number of mice in each group is shown. Data are expressed as means \pm SEM $(\mathbf{A}-\mathbf{D}) .{ }^{*} P<0.05,{ }^{* *} P<0.01$, and ${ }^{* * *} P<0.001 ;{ }^{\dagger \dagger} P<0.01,{ }^{\dagger \dagger \dagger} P<0.001$, and ${ }^{\dagger \dagger \dagger \dagger} P<0.0001$ versus $A b c c 6^{-1-}$ mice at corresponding time points. 

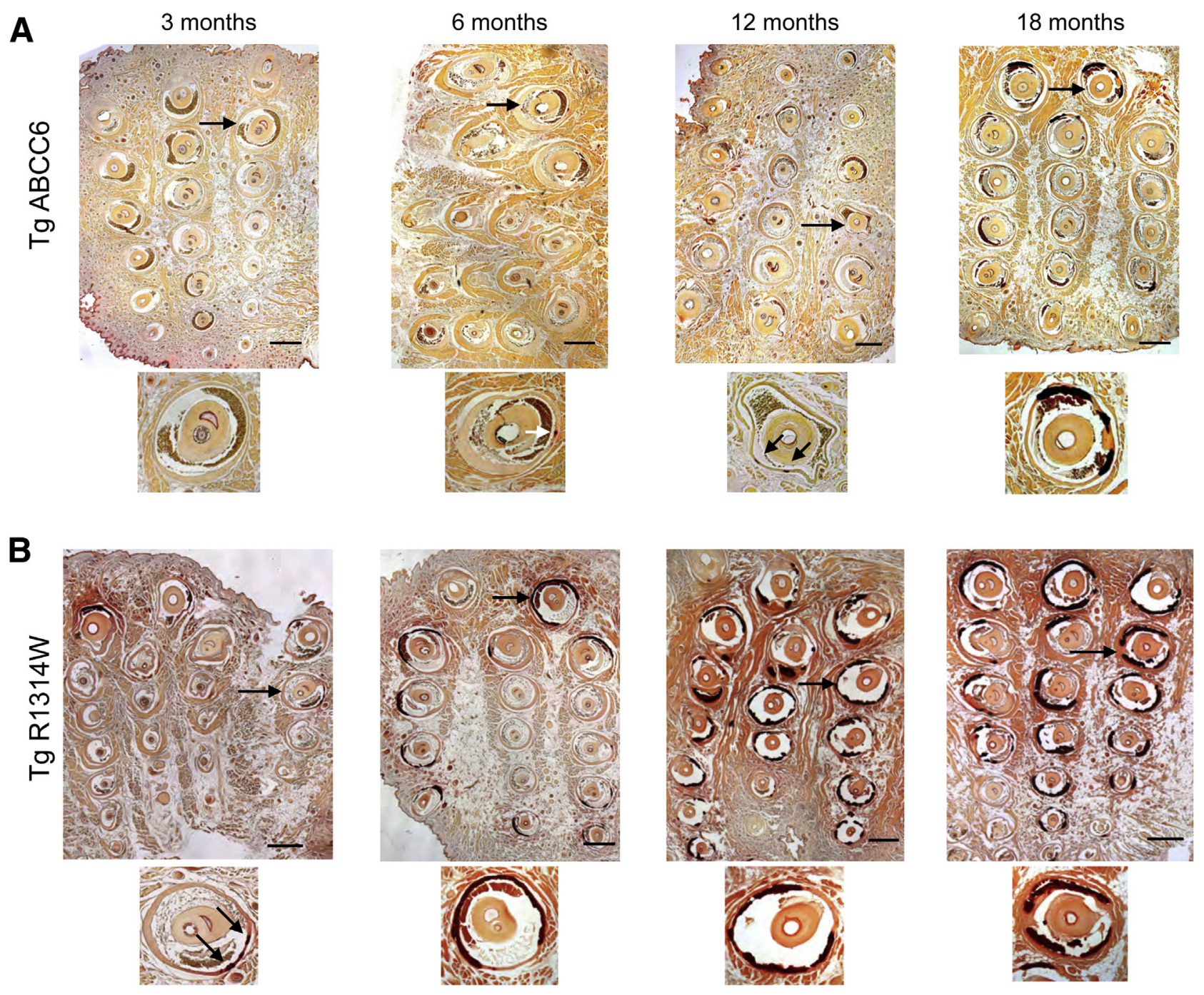

Figure 7 Histological evaluation of vibrissae calcification in $A b c c 6^{-/-}$transgenic mice. The positive effects of both transgenes (normal ABCC6 and R1314W variant) on the calcification of vibrissae (chronic pseudoxanthoma elasticum-like phenotype) was evaluated by Alizarin Red S staining (red to dark red color). A: Representative images of whiskers from 3- to 18-month-old $A b c c 6^{-1-}$ transgenic $(\mathrm{Tg})$ mice carrying the normal human ABCC6 gene are shown. B: Representative images are from whiskers of $A b c c 6^{-/-}$mice with the $A B C C 6$ R1314W transgene are shown. A higher magnification image of a selected vibrissa (arrows) is shown below each larger panel (A and $\mathbf{B})$. Arrows within the higher magnification images point to discrete calcification spots (A and $\mathbf{B})$. Scale bars $=500 \mu \mathrm{m}(\mathbf{A}$ and $\mathbf{B})$. Original magnification, $\times 200$ (higher magnification images).

Reduced plasma PPi levels have been associated with the mineralization phenotype of several heritable or acquired conditions, including PXE. ${ }^{7,10,22,48,50,51}$ PPi supplementation using various modes of delivery in several animal models has proved to be an effective treatment toward the attenuation of pathological calcification of different etiology. ${ }^{22,24,52}$ Herein, we found that a single daily i.p. dose of PPi was also effective at preventing the development of both forms of ectopic mineralization linked to ABCC6 deficiency, the acute dystrophic cardiac calcification, and chronic PXE-like manifestations associated with vibrissae calcification. This approach produced a large but temporary excess of PPi (sixfold above normal levels) in the plasma, which was resolved after several hours through a typical first-order kinetic. Interestingly, alkaline phosphatase levels in plasma were significantly reduced in young
$A b c c 6^{-/-}$mice but not in older animals. Even though the reason for this difference is unclear, it did not have much impact on PPi concentration in plasma at any age. PPi tissue levels are the result of a balance of in situ production and hydrolysis as well as peritoneal absorption and diffusion from the blood. Therefore, the inhibitory effect we observed on acute and chronic calcification is presumably because of PPi extravasation increasing local concentrations. Indeed, myocardium, vibrissae, ${ }^{53}$ and renal tissues are highly vascularized. Because PPi decays rapidly in plasma, it is likely that tissue concentrations also decrease accordingly. Previous studies indicated that dystrophic cardiac calcification develops in a few days. ${ }^{16,30}$ Our experiment with a single bolus of PPi injected quickly after cardiac lesion indicates that the mineralization process leading to the DCC phenotype is initiated within minutes after injury. Unlike DCC, 


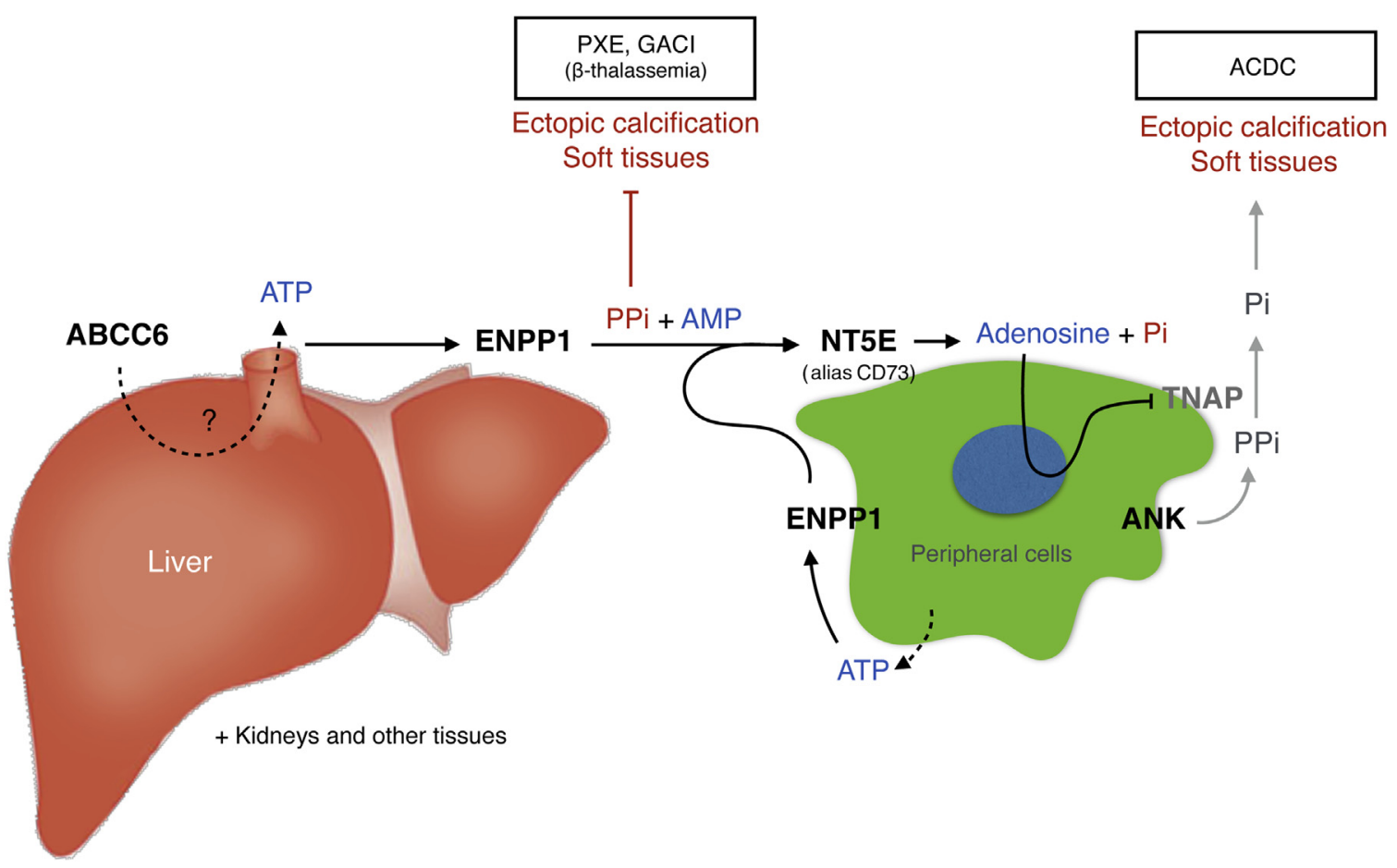

Figure 8 A possible model for ABCC6-dependent pyrophosphate generation and inhibition of ectopic calcification. ABCC6 facilitates the release of ATP from the liver (and other tissues), which is converted into the calcification inhibitor pyrophosphate (PPi) and adenosine monophosphate (AMP) by ectonucleotide pyrophosphatase-phosphodiesterase 1 (ENPP1). Ecto-5'-nucleotidase (NT5E; alias CD73) converts AMP into adenosine, which is an inhibitor of tissue-nonspecific alkaline phosphatase (TNAP) synthesis. In peripheral tissues, such as bone, PPi is released by progressive ankylosis protein (ANK) and hydrolyzed into inorganic phosphate (Pi) by TNAP. ABCC6 deficiency causes pseudoxanthoma elasticum (PXE) and some cases of generalized arterial calcification of infancy (GACI). Mutations in ENPP1 primarily lead to GACI and also some cases of PXE. Nonfunctional ecto-5'-nucleotidase (NT5E) results in arterial calcification because of deficiency of CD73 (ACDC).

the chronic PXE-like calcification of $A b c c 6^{-1-}$ mice develops slowly over several months. ${ }^{32}$ Intriguingly, this spontaneous calcification can be effectively prevented by a single daily dose of PPi. One could argue that because of the short half-life of $\mathrm{PPi}$, tissue concentrations in mice decreased rapidly below normal levels for most of the 24-hour period between injections, during which hydroxyapatite crystals could, in principle, continue to grow. However, we found that intermittent correction of PPi deficiency inhibits ectopic calcification as efficiently as a continuous infusion. ${ }^{23}$ This suggests that PPi effects on calcification might involve other processes than physical interaction with hydroxyapatite crystals. We speculate that PPi could also promote a cellular environment prohibiting mineralization. In support of this hypothesis, a previous report suggested such a role for $\mathrm{PP}^{50}$ and a recently completed study from one of us (Z.A.) indicates that PPi inhibits the osteogenic differentiation of macrophagederived multinucleated cells (C.B., O.L.S., C.B., R. Aherrahrou, R. Kriesen, S. Stölting, T. Kessler, H. Schunkert, J.E., Z.A., unpublished data).

The results obtained with transgenic animals substantiate further the influence that ABCC6 function has on circulating PPi and are consistent with the data from the exogenous administration of PPi. These data support the notion that a modest increase in plasma PPi has a dramatic impact on ectopic calcification. Remarkably, these experiments also revealed that the ABCC6 R1314W mutant had nonnegligible residual physiological function toward calcification inhibition. Although the plasma PPi concentration in the $\mathrm{R} 1314 \mathrm{~W}$ transgenic mice was raised by a small margin as compared to $A b c c \sigma^{-1-}$ mice, it was not statistically significant with the number of animals we used. We have previously shown that this mutant displays normal transport activity in vitro but that a majority of the protein is retained intracellularly in vivo. ${ }^{27,36}$ It is therefore possible that a minor fraction of this mutant still reaches the plasma membrane and thus contributes to some PPi production. Considering the inherent difficulties of measuring PPi in biological fluids, ${ }^{48,54}$ it is conceivable that this small but possibly meaningful variation in circulating PPi fell within the margin of error of our method.

In this study, we have also explored whether bisphosphonates could inhibit DCC using $A b c c 6^{-1-}$ mice. Etidronate and alendronate treatments were previously tested on the chronic calcification of $A b c c 6^{-/-}$mice and only etidronate showed inhibitory effects, albeit with large dosage. ${ }^{18,35,55}$ In this study, we found that etidronate treatment was effective at preventing DCC. Etidronate was also efficient for GACI treatment; however, bisphosphonates have pleiotropic effects on cellular functions and other undesirable long-term adverse effects. ${ }^{17}$ Because the DCC phenotype has only been 
described in mice thus far, ${ }^{6}$ these stable analogs of PPi represent an unlikely life-long treatment option for PXE.

Despite the availability of palliative treatment ${ }^{56}$ there is currently no cure for PXE. However, we and others have made significant progress in understanding the biology of ABCC6 and its physiological role, and several studies of possible therapeutic solution are now emerging. For example, the potential of the PTC-124 drug for rescuing the most common ABCC6 p.R1141X variant ${ }^{57}$ has recently been tested, but the actual translational value of this approach is still unclear. The preliminary results of a 2-year clinical trial testing magnesium oxide supplementation to reverse calcification in PXE patients were not encouraging (PXE Conference, September 15 to 17, 2016, in Philadelphia, PA). We have also shown in a humanized mouse model of PXE that the chemical chaperone 4-phenylbutyrate rescues the defective cellular localization of missense ABCC6 mutants ${ }^{27,36}$ and their calcification inhibition potential. ${ }^{47}$ The present study showed that increasing circulating PPi intermittently and/or by small amounts via supplementation was effective against ectopic mineralization and could be a useful approach to treat all PXE patients irrespective of their genotype or disease state. This could also have broader application for GACI patients and $\beta$ thalassemia patients with PXE-like manifestations as PPi is a common food additive and has no major toxicity with an $\mathrm{LD}_{50}$ in rodents of $>5.83 \mathrm{mmol} / \mathrm{kg}(2600 \mathrm{mg} / \mathrm{kg}) .{ }^{58}$ However, several questions related to dosage, method, frequency of delivery, and possible long-term effects on bone physiology will need to be addressed before any clinically relevant application could be tested. And more important, as we found that PPi treatment does not reverse established calcification, the efficacy of such treatment will depend on the time at which it is initiated, and the earlier seems the better.

Collectively, our findings showed the central role that ABCC6 plays in PXE by modulating ENPP1 expression and plasma PPi. This places ABCC6 as an upstream regulator of the ENPP1 $\rightarrow$ NT5E pathway that inhibits mineralization (Figure 8). The clinical manifestations associated with this pathway are in fact a spectrum of related diseases that include PXE and GACI but also arterial calcification due to CD73 (NT5E) deficiency (ACDC), ${ }^{59}$ all characterized by substantial calcification in cardiovascular and other tissues.

\section{Acknowledgments}

We thank Dr. Piet Borst for comments on the manuscript and Dr. Mark A. Kay (Stanford University) for the liverspecific promoter.

\section{Supplemental Data}

Supplemental material for this article can be found at http://dx.doi.org/10.1016/j.ajpath.2017.02.009.

\section{References}

1. Atzeni F, Sarzi-Puttini P, Bevilacqua M: Calcium deposition and associated chronic diseases (atherosclerosis, diffuse idiopathic skeletal hyperostosis, and others). Rheum Dis Clin North Am 2006, 32: 413-426. viii

2. Beck K, Hayashi K, Nishiguchi B, Le Saux O, Hayashi M, Boyd CD: The distribution of Abcc6 in normal mouse tissues suggests multiple functions for this ABC transporter. J Histochem Cytochem 2003, 51: 887-902

3. Ilias A, Urban Z, Seidl TL, Le Saux O, Sinko E, Boyd CD, Sarkadi B, Varadi A: Loss of ATP-dependent transport activity in pseudoxanthoma elasticum-associated mutants of human ABCC6 (MRP6). J Biol Chem 2002, 277:16860-16867

4. Bergen AA, Plomp AS, Schuurman EJ, Terry S, Breuning M, Dauwerse H, Swart J, Kool M, van Soest S, Baas F, ten Brink JB, de Jong PT: Mutations in ABCC6 cause pseudoxanthoma elasticum. Nat Genet 2000, 25:228-231

5. Le Saux O, Urban Z, Tschuch C, Csiszar K, Bacchelli B, Quaglino D, Pasquali-Ronchetti I, Pope FM, Richards A, Terry S, Bercovitch L, de Paepe A, Boyd CD: Mutations in a gene encoding an ABC transporter cause pseudoxanthoma elasticum. Nat Genet 2000, 25: 223-227

6. Le Saux O, Martin L, Aherrahrou Z, Leftheriotis G, Varadi A, Brampton CN: The molecular and physiological roles of ABCC6: more than meets the eye. Front Genet 2012, 3:289

7. Jansen RS, Duijst S, Mahakena S, Sommer D, Szeri F, Varadi A, Plomp A, Bergen AA, Oude Elferink RP, Borst P, van de Wetering K: ABCC6-mediated ATP secretion by the liver is the main source of the mineralization inhibitor inorganic pyrophosphate in the systemic circulation: brief report. Arterioscler Thromb Vasc Biol 2014, 34:1985-1989

8. Jansen RS, Kucukosmanoglu A, de Haas M, Sapthu S, Otero JA, Hegman IE, Bergen AA, Gorgels TG, Borst P, van de Wetering K: ABCC6 prevents ectopic mineralization seen in pseudoxanthoma elasticum by inducing cellular nucleotide release. Proc Natl Acad Sci U S A 2013, 110:20206-20211

9. Sidhu H, Gupta R, Thind SK, Nath R: Inhibition of calcium oxalate monohydrate (COM) crystal growth by pyrophosphate, citrate and rat urine. Urol Res 1986, 14:299-303

10. Lomashvili KA, Cobbs S, Hennigar RA, Hardcastle KI, O'Neill WC: Phosphate-induced vascular calcification: role of pyrophosphate and osteopontin. J Am Soc Nephrol 2004, 15:1392-1401

11. Le Saux O, Beck K, Sachsinger C, Silvestri C, Treiber C, Göring HH, Johnson EW, De Paepe A, Pope FM, Pasquali-Ronchetti I, Bercovitch L, Terry S, Boyd CD: A spectrum of abcc6 mutations is responsible for pseudoxanthoma elasticum. Am J Hum Genet 2001, 69:749-764

12. Nitschke Y, Baujat G, Botschen U, Wittkampf T, du Moulin M, Stella J, Le Merrer M, Guest G, Lambot K, Tazarourte-Pinturier MF, Chassaing N, Roche O, Feenstra I, Loechner K, Deshpande C, Garber SJ, Chikarmane R, Steinmann B, Shahinyan T, Martorell L, Davies J, Smith WE, Kahler SG, McCulloch M, Wraige E, Loidi L, Hohne W, Martin L, Hadj-Rabia S, Terkeltaub R, Rutsch F: Generalized arterial calcification of infancy and pseudoxanthoma elasticum can be caused by mutations in either ENPP1 or ABCC6. Am J Hum Genet 2012, 90:25-39

13. Hamlin N, Beck K, Bacchelli B, Cianciulli P, Pasquali-Ronchetti I, Le Saux O: Acquired pseudoxanthoma elasticum-like syndrome in beta-thalassaemia patients. Br J Haematol 2003, 122:852-854

14. Martin L, Douet V, Vanwart CM, Heller MB, Le Saux O: A mouse model of beta-thalassemia shows a liver-specific down-regulation of Abcc6 expression. Am J Pathol 2011, 178:774-783

15. Aherrahrou Z, Doehring LC, Ehlers EM, Liptau H, Depping R, Linsel-Nitschke P, Kaczmarek PM, Erdmann J, Schunkert H: An alternative splice variant in Abcc6, the gene causing dystrophic 
calcification, leads to protein deficiency in $\mathrm{C} 3 \mathrm{H} / \mathrm{He}$ mice. J Biol Chem 2008, 283:7608-7615

16. Brampton C, Aherrahrou Z, Chen LH, Martin L, Bergen AA, Gorgels TG, Erdmann J, Schunkert H, Szabo Z, Varadi A, Le Saux O: The level of hepatic ABCC6 expression determines the severity of calcification after cardiac injury. Am J Pathol 2014, 184:159-170

17. Otero JE, Gottesman GS, McAlister WH, Mumm S, Madson KL, Kiffer-Moreira T, Sheen C, Millan JL, Ericson KL, Whyte MP: Severe skeletal toxicity from protracted etidronate therapy for generalized arterial calcification of infancy. J Bone Miner Res 2013, 28: 419-430

18. Li Q, Sundberg JP, Levine MA, Terry SF, Uitto J: The effects of bisphosphonates on ectopic soft tissue mineralization caused by mutations in the ABCC6 gene. Cell Cycle 2015, 14:1082-1089

19. Fleisch H, Bisaz S: Isolation from urine of pyrophosphate, a calcification inhibitor. Am J Physiol 1962, 203:671-675

20. Fleisch H, Bisaz S: Mechanism of calcification: inhibitory role of pyrophosphate. Nature 1962, 195:911

21. Lomashvili KA, Monier-Faugere MC, Wang X, Malluche HH, O'Neill WC: Effect of bisphosphonates on vascular calcification and bone metabolism in experimental renal failure. Kidney Int 2009, 75: $617-625$

22. O'Neill WC, Lomashvili KA, Malluche HH, Faugere MC, Riser BL: Treatment with pyrophosphate inhibits uremic vascular calcification. Kidney Int 2011, 79:512-517

23. Riser BL, Barreto FC, Rezg R, Valaitis PW, Cook CS, White JA, Gass JH, Maizel J, Louvet L, Drueke TB, Holmes CJ, Massy ZA: Daily peritoneal administration of sodium pyrophosphate in a dialysis solution prevents the development of vascular calcification in a mouse model of uraemia. Nephrol Dial Transplant 2011, 26: $3349-3357$

24. Villa-Bellosta R: Vascular calcification revisited: a new perspective for phosphate transport. Curr Cardiol Rev 2015, 11:341-351

25. Gorgels TG, Hu X, Scheffer GL, van der Wal AC, Toonstra J, de Jong PT, van Kuppevelt TH, Levelt CN, de Wolf A, Loves WJ, Scheper RJ, Peek R, Bergen AA: Disruption of Abcc6 in the mouse: novel insight in the pathogenesis of pseudoxanthoma elasticum. Hum Mol Genet 2005, 14:1763-1773

26. Committee for the Update of the Guide for the Care and Use of Laboratory Animals; National Research Council: Guide for the Care and Use of Laboratory Animals: Eighth Edition. Washington, DC, National Academies Press, 2011

27. Le Saux O, Fulop K, Yamaguchi Y, Ilias A, Szabo Z, Brampton CN, Pomozi V, Huszar K, Aranyi T, Varadi A: Expression and in vivo rescue of human ABCC6 disease-causing mutants in mouse liver. PLoS One 2011, 6:e24738

28. Liu F, Song Y, Liu D: Hydrodynamics-based transfection in animals by systemic administration of plasmid DNA. Gene Ther 1999, 6: $1258-1266$

29. Zhang G, Gao X, Song YK, Vollmer R, Stolz DB, Gasiorowski JZ, Dean DA, Liu D: Hydroporation as the mechanism of hydrodynamic delivery. Gene Ther 2004, 11:675-682

30. Aherrahrou Z, Axtner SB, Kaczmarek PM, Jurat A, Korff S, Doehring LC, Weichenhan D, Katus HA, Ivandic BT: A locus on chromosome 7 determines dramatic up-regulation of osteopontin in dystrophic cardiac calcification in mice. Am J Pathol 2004, 164: 1379-1387

31. Ivandic BT, Utz HF, Kaczmarek PM, Aherrahrou Z, Axtner SB, Klepsch C, Lusis AJ, Katus HA: New Dyscalc loci for myocardial cell necrosis and calcification (dystrophic cardiac calcinosis) in mice. Physiol Genomics 2001, 6:137-144

32. Brampton C, Yamaguchi Y, Vanakker O, Van Laer L, Chen LH, Thakore M, De Paepe A, Pomozi V, Szabo PT, Martin L, Varadi A, Le Saux O: Vitamin K does not prevent soft tissue mineralization in a mouse model of pseudoxanthoma elasticum. Cell Cycle 2011, 10: $1810-1820$
33. McGee-Russell SM: Histochemical methods for calcium. J Histochem Cytochem 1958, 6:22-42

34. Hashimoto K, Morishige K, Sawada K, Tahara M, Kawagishi R, Ikebuchi Y, Sakata M, Tasaka K, Murata Y: Alendronate inhibits intraperitoneal dissemination in in vivo ovarian cancer model. Cancer Res 2005, 65:540-545

35. Li Q, Kingman J, Sundberg JP, Levine MA, Uitto J: Etidronate prevents, but does not reverse, ectopic mineralization in a mouse model of pseudoxanthoma elasticum (Abcc6-/-). Oncotarget 2016. doi:10.18632/oncotarget.10738, [Epub ahead of print]

36. Pomozi V, Brampton C, Fulop K, Chen LH, Apana A, Li Q, Uitto J, Le Saux O, Varadi A: Analysis of pseudoxanthoma elasticum-causing missense mutants of ABCC6 in vivo: pharmacological correction of the mislocalized proteins. J Invest Dermatol 2014, 134:946-953

37. Marh J, Stoytcheva Z, Urschitz J, Sugawara A, Yamashiro H, Owens JB, Stoytchev I, Pelczar P, Yanagimachi R, Moisyadi S: Hyperactive self-inactivating piggyBac for transposase-enhanced pronuclear microinjection transgenesis. Proc Natl Acad Sci U S A 2012, 109:19184-19189

38. Urschitz J, Kawasumi M, Owens J, Morozumi K, Yamashiro H, Stoytchev I, Marh J, Dee JA, Kawamoto K, Coates CJ, Kaminski JM, Pelczar P, Yanagimachi R, Moisyadi S: Helper-independent piggyBac plasmids for gene delivery approaches: strategies for avoiding potential genotoxic effects. Proc Natl Acad Sci U S A 2010, 107: $8117-8122$

39. Anderson CD, Moisyadi S, Avelar A, Walton CB, Shohet RV: U1trasound-targeted hepatic delivery of factor IX in hemophiliac mice. Gene Ther 2016, 23:510-519

40. Miao CH, Ohashi K, Patijn GA, Meuse L, Ye X, Thompson AR, Kay MA: Inclusion of the hepatic locus control region, an intron, and untranslated region increases and stabilizes hepatic factor IX gene expression in vivo but not in vitro. Mol Ther 2000, 1:522-532

41. Yusa K, Zhou L, Li MA, Bradley A, Craig NL: A hyperactive piggyBac transposase for mammalian applications. Proc Natl Acad Sci U S A 2011, 108:1531-1536

42. Miglionico R, Armentano MF, Carmosino M, Salvia AM, Cuviello F, Bisaccia F, Ostuni A: Dysregulation of gene expression in ABCC6 knockdown HepG2 cells. Cell Mol Biol Lett 2014, 19:517-526

43. Russell RG: Bisphosphonates: from bench to bedside. Ann N Y Acad Sci 2006, 1068:367-401

44. Le Corre Y, Le Saux O, Froeliger F, Libouban H, Kauffenstein G, Willoteaux S, Leftheriotis G, Martin L: Quantification of the calcification phenotype of abcc6-deficient mice with microcomputed tomography. Am J Pathol 2012, 180:2208-2213

45. Li Q, Guo H, Chou DW, Berndt A, Sundberg JP, Uitto J: Mouse models for pseudoxanthoma elasticum: genetic and dietary modulation of the ectopic mineralization phenotypes. PLoS One 2014, 9: e89268

46. Klement JF, Matsuzaki Y, Jiang QJ, Terlizzi J, Choi HY, Fujimoto N, Li K, Pulkkinen L, Birk DE, Sundberg JP, Uitto J: Targeted ablation of the abcc6 gene results in ectopic mineralization of connective tissues. Mol Cell Biol 2005, 25:8299-8310

47. Pomozi V, Brampton C, Szeri F, Debinszki D, Kozák E, van de Wetering K, Hopkins H, Martin L, Varadi A, Le Saux O: Functional rescue of ABCC6 deficiency by 4-phenylbutyrate therapy reduces dystrophic calcification in Abcc6-/- mice. J Invest Dermatol 2017, 137:595-602

48. O'Neill WC, Sigrist MK, McIntyre CW: Plasma pyrophosphate and vascular calcification in chronic kidney disease. Nephrol Dial Transplant 2010, 25:187-191

49. Terkeltaub RA: Inorganic pyrophosphate generation and disposition in pathophysiology. Am J Physiol Cell Physiol 2001, 281:C1-C11

50. Addison WN, Azari F, Sorensen ES, Kaartinen MT, McKee MD: Pyrophosphate inhibits mineralization of osteoblast cultures by binding to mineral, up-regulating osteopontin, and inhibiting alkaline phosphatase activity. J Biol Chem 2007, 282:15872-15883 
51. Lomashvili KA, Narisawa S, Millan JL, O'Neill WC: Vascular calcification is dependent on plasma levels of pyrophosphate. Kidney Int 2014, 85:1351-1356

52. Villa-Bellosta R, Rivera-Torres J, Osorio FG, Acin-Perez R, Enriquez JA, Lopez-Otin C, Andres V: Defective extracellular pyrophosphate metabolism promotes vascular calcification in a mouse model of Hutchinson-Gilford progeria syndrome that is ameliorated on pyrophosphate treatment. Circulation 2013, 127:2442-2451

53. Kim JN, Koh KS, Lee E, Park SC, Song WC: The morphology of the rat vibrissal follicle-sinus complex revealed by three-dimensional computer-aided reconstruction. Cells Tissues Organs 2011, 193: 207-214

54. Russell RG, Bisaz S, Donath A, Morgan DB, Fleisch H: Inorganic pyrophosphate in plasma in normal persons and in patients with hypophosphatasia, osteogenesis imperfecta, and other disorders of bone. J Clin Invest 1971, 50:961-969

55. Li Q, Kingman J, Sundberg JP, Levine MA, Uitto J: Dual effects of bisphosphonates on ectopic skin and vascular soft tissue mineralization versus bone microarchitecture in a mouse model of generalized arterial calcification of infancy. J Invest Dermatol 2016, $136: 275-283$

56. Finger RP, Charbel Issa P, Schmitz-Valckenberg S, Holz FG, Scholl HN: Long-term effectiveness of intravitreal bevacizumab for choroidal neovascularization secondary to angioid streaks in pseudoxanthoma elasticum. Retina 2011, 31:1268-1278

57. Zhou Y, Jiang Q, Takahagi S, Shao C, Uitto J: Premature termination codon read-through in the ABCC6 gene: potential treatment for pseudoxanthoma elasticum. J Invest Dermatol 2013, 133:2672-2677

58. Seo DS, Kwon M, Sung HJ, Park CB: Acute oral or dermal and repeated dose 90-day oral toxicity of tetrasodium pyrophosphate in Spraque Dawley (SD) rats. Environ Health Toxicol 2011, 26:e2011014

59. Markello TC, Pak LK, St Hilaire C, Dorward H, Ziegler SG, Chen MY, Chaganti K, Nussbaum RL, Boehm M, Gahl WA: Vascular pathology of medial arterial calcifications in NT5E deficiency: implications for the role of adenosine in pseudoxanthoma elasticum. Mol Genet Metab 2011, 103:44-50 